\title{
Factors influencing the usage of XBRL tools
}

\author{
Badi Salem Rawashdeh ${ }^{\mathrm{a}}$ and Awni Rawashdeh ${ }^{\mathrm{b} *}$
}

${ }^{a}$ Arab Open University, Saudi Arabia

${ }^{b}$ Petra University, Jordan

\section{H R O N I C L E}

\begin{tabular}{l} 
Article history: \\
Received: July 10,2020 \\
Received in revised format: \\
October 182020 \\
Accepted: November 4,2020 \\
Available online: \\
November 4,2020 \\
\hline Keywords: \\
XBRL \\
XBRL Tools \\
UTUAT \\
SEM \\
Factors \\
Influencing \\
Usage \\
Users \\
Financial Reporting \\
Adoption
\end{tabular}

\section{A B S T R A C T}

This study established and empirically validated a model for predicting factors influencing users' behavioural intentions for using XBRL tools. This study explored the behavioural intention of using XBRL tools from the point of view of users by applying the UTAUT model with the addition of trust and satisfaction. An online survey was conducted by using the modified study model to comply with the research objectives. An on-line survey of 267 respondents obtained and analysed using structural equation modelling (SEM) and IBM SPSS AMOS. The findings show that trust and satisfaction influenced behavioural intent significantly and positively. In turn, the effort expectancy and performance expectancy had a significant impact on satisfaction. The results showed that in the presence of satisfaction there was no direct effect of effort expectancy and performance expectancy on the behavioural intention to use XBRL tools and the emergence of a direct effect of confidence on the behavioural intention to use XBRL tools. The findings correspond with the previous studies and provide a practical reference for XBRL tool developers and decision-makers involved in developing and using XBRL tools for tagging and analysing financial reporting.

(C) 2021 by the authors; licensee Growing Science, Canada

\section{Introduction}

With the recent rapid advancement in digital financial repotting, not only changed the type of disclosure of financial statements but also changed the tools of disclosure previously were paper, Excel, PDF, or HTML now became XBRL (Al-Rawashdeh, 2011). XBRL gives companies the ability to comply with regulations using the XBRL tools that they prefer to work with companies now use a new tool for preparing the data to XBRL public company disclosure. Thus, XBRL tools are crucial for disclosure about the face of the financial statements and related footnotes (Blankespoor, 2019). The XBRL Tool is a software that supports the XBRL tagging process and preparation of XBRL documents. These tools have considerable potential that provides new possibilities for financial statements and footnotes that are not available in non-XBRL formats (Efimova et al., 2019). XBRL tools can enhance reporting and analysis quality and users' decision quality. XBRL is an XML-based vocabulary for electronic transmission of financial and non-financial data; each item is enclosed by a pair of XBRL tags. XBRL is an open standard that is maintained by XBRL International. With support from the governing bodies worldwide have secured XBRL as the official standard for financial reporting. Saudi Arabia is no exception, Tadawul has adopted XBRL as new technology to ensure equal access to corporate disclosures and enable users to analyse financial statements fairly among all users (Rawashdeh \& Selamat, 2013). XBRL tool is a critical software of users, and thus its acceptance and usage receive growing interest for users, companies, and providers. Moreover, recent studies (Liu et al., 2017; Tohang \& Lan, 2017; Ilias et al., 2020) have indicated that many countries have adopted XBRL. However, users' interest, acceptance, and usage of the XBRL tools are not well known unlike XBRL itself as a global framework for exchanging business information. Thus, * Corresponding author.

E-mail address: drxbrl@yaho.com (A. Rawashdeh) 
investigating the factors affecting users' acceptance of XBRL tools and their intentions to use them in a wide way is critical. Therefore, this study examined the behavioural intentions of users to use XBRL tools. In the context of information systems and information technology, the widespread use of new technology tools relies on user acceptance (Davis, 1989). In recent years, several researchers have been able to develop various theories and models for predicting the behaviour of users towards adopting new technology or systems in different areas. The technology acceptance model (TAM) is among the most used models when reviewing the adoption and diffusion literature (Wu \& Chen, 2005; Chouhan \& Goswami, 2015; Althunibat et al., 2019; Baby \& Kannammal, 2020). Although TAM has been used a lot by researchers (Wu \& Chen, 2005; Chouhan \& Goswami, 2015; Althunibat et al., 2019; Baby \& Kannammal, 2020) and still is, in the end, some negative aspects appeared in this model.

In a new attempt to overcome the negative aspects of the TAM model, to obtain a more realistic model Venkatesh et al. (2003) integrated several common factors from eight models and prominent theories. These include the social cognitive theory [SCT], the theory of planned behaviour [TPB], innovation diffusion theory [IDT], the TAM; the motivational model (MM), the combined TAM-TPB, the model of PC utilization [MPCU], and the theory of reasoned action [TRA]. To create a new technology adoption, acceptance, and usage model. This combination of carefully selected variables is called the unified theory of acceptance and use of technology (UTAUT) model. Recently, the UTAUT model is a widely used model for forecasting acceptance and usage of technology and new systems. The UTAUT model has been applied in various fields. For example, the adoption of mobile payment (Patil et al., 2020), The adoption of a social learning system (Khechine et al., 2020), acceptance of mobile health (Petersen et al., 2020), acceptance of Mobile learning system (Almaiah et al., 2019; Chao, 2019), web 2.0 tools (Gitau, 2016) and acceptance of software engineering tools (Wrycza et al., 2017). The previous researches are a sample of the widespread use of the UTAUT model, the UTAUT model provides high flexibility that enables it to be used in multiple fields. This flexibility stems from the ability of this model to integrate several theories and models into a fairly acceptable model.

Despite the structure on which the UTAUT model is built, but the model has faced some criticism in its ability to explain individuals 'acceptance of technology-based systems, criticism makes sense if we consider that humans and technology are constantly evolving. Therefore, several researchers believe that the original UTAUT model should be expanded if necessary according to the nature of the research in question. Some of them added to it some variables as an attempt to calm doubts about the ability of the model to predict the acceptance of technology-based systems by individuals. For example, some researchers (Taiwo et al., 2012; Chao, 2019; Rahi et al., 2019; Manrai \& Gupta, 2020) suggest adding other internal and external factors that could enhance the model's ability to predict the acceptance of technology-based systems. XBRL tools handle quantities of data. There are many types of XBRL tools, including coding financial data, validating data, and financial analysis. Therefore, there are various users of XBRL tools and they use XBRL for a variety of purposes. XBRL tools are used to process sensitive financial data, any error that may affect the financial position of the company, and used for financial analysis and any error that may lead to making a wrong investment decision. For purposes of this research, it is expected that adding trust and satisfaction factors to the original UTAUT model will play an important role in accepting and using XBRL tools. For example, the trust factor was incorporated as a predictor in the model by several researchers (Manrai \& Gupta, 2020). According to a previous study on the adoption of online tax filing (Carter et al., 2011), trust is a vital factor in determining users' behavioural intentions to adopt technology-based systems.

For this research, the UTAUT has been adopted and expanded by incorporating trust and satisfaction factors. To investigate the behavioural intentions of users toward the use of XBRL tools in preparing and validating, and analyzing financial statements and footnotes. Adopting XBRL as a global framework for exchanging business information differs from adopting XBRL tools, in the case of XBRL, there is one framework called XBRL and there is no other option. However, in the case of XBRL tools, there are many tools available for a variety of purposes and thus the investigation of the factors affecting XBRL tools may differ from the investigation of the factors that affect the adoption of XBRL as a global framework for exchanging business information that can be adopted. Therefore, this research aims to investigate the factors affecting the behavioural intention to use XBRL tools. In addition to developing an expanded model, that contains trust and satisfaction. This research also aims to prove that satisfaction is a mediating and predictive variable of the behavioural intentions of users to use XBRL tools. Finally, the research aims to confirm the model experimentally in this context. To achieve the aims of the research, the following four research questions were formulated.

(1) What factors affect the behavioural intentions of users affecting the use of XBRL tools?

(2) Does trust affect the UTAUT model regarding XBRL tools?

(3) Does satisfaction affect the UTAUT model regarding the use of XBRL tools?

(4) How can both trust and satisfaction affect the expectation of behavioural intention to use XBRL tools?

Most of the previous studies focus on adopting XPRL as a global framework for exchanging business information. Since XPRL tools are available in most companies, this research is projected to contribute the related literature to the acceptance and use of technology-based systems by determining trust as a precedent for the use of XBRL tools. Promote and deepen the theoretical understanding regarding the behavioural intention among users regarding the use of XBRL tools for analytical purposes. Provide empirical evidence on the role of satisfaction as a mediating variable that links the internal and external 
factors and behavioural intentions of users to use XBRL tools. Providing a reference to specialized developers of the XBRL tools on future directions of users related to using XBRL tools.

\section{Literature Review}

\subsection{XBRL Adoption}

Most of the previous studies in this region focus on adopting the XBRL itself and not focusing on adopting the XBRL tools. Ilias et al. (2020) investigated several factors that can effect on XBRL adoption in Malaysia, which are, optimism, innovativeness, discomfort, insecurity, and intention to Use. Uyob et al. (2019) analysed consumer attitude variables concerning MBRS use. The results of this research suggest that perceived usefulness and ease of use are factors that affect the accounting practitioners' attitude to use MBRS. Rawashdeh and Selamat (2013) examined the various normative, attitudinal, and control factors influencing the adopters' intention to accept XBRL in Saudi Arabia. Pinsker and Felden (2016) examine voluntary XBRL adoption intent in Germany; results indicate that professional role and normative pressure have positive relationships with XBRL adoption intent. Lakovic et al. (2018) investigated the determinants of XBRL adoption, their results refer that environmental factors, technical factors, and organizational factors influence the XBRL adoption. Muchlis et al. (2019)analysed the factors influencing early adopters in Indonesia during the early phase of XBRL. They found that the size and profitability of a firm are the financial characteristics of the firm, which determine the early adoption of XBRL. Alkhatib et al. (2019) examined the factors influencing the voluntary adoption of the statutory accounts digital reporting and the return of small private companies in the UK. Their findings indicate that the relative benefit of standardization, support from top management and the company's technology competence factors had a significant effect on the voluntary adoption of digital technologies. Previous studies try to explain what factors can influence XBRL adoption. However, Studies covering XPRL adoption are almost missing from previous studies. In a meta-analysis, Ansary et al. (2020) tried to determine the determinants of XBRL adoption. They divided determinants of XBRL adoption into three primary factor groups: Perceived usability regarding the technical aspect, perceived usefulness and ease-of-use. The second aspect considers environmental factors such as normative pressure. The third dimension is the organizational aspect, which consists of the managerial attitude and organizational expertise. Findings have seemed contrasting to date.

\subsection{UTAUT Model}

Venkatesh et al. (2003) in an in-depth study of a reputable group of theories and models used in the framework of technology adoption. They studied a set of variables that were compiled from these theories and models that are called use in the context of information technology. Through this experimental study of these selected variables, the researchers came up with a model from their point of view, which is considered an ideal model for standardizing models and theories related to accepting technology into one unified model called the UTAUT model (Table 1).

\section{Table 1}

Core factors and definitions

\begin{tabular}{|c|c|}
\hline Core factors & Definitions \\
\hline Performance expectancy (PE) & $\begin{array}{l}\text { "The degree to which an individual believes that using the system will help him or her attain gains in job } \\
\text { performance" (Venkatesh et al., 2003) }\end{array}$ \\
\hline Effort expectancy (EE) & "The degree of ease associated with the use of the system" (Venkatesh et al., 2003) \\
\hline Social influence (SI) & $\begin{array}{l}\text { "The degree to which an individual perceives that important others believe he or she should use the new sys- } \\
\text { tem" (Venkatesh et al., 2003) }\end{array}$ \\
\hline Facilitating conditions $(\mathrm{FC})$ & $\begin{array}{l}\text { "The degree to which an individual believes that an organizational and technical infrastructure exists to support } \\
\text { use of the system" (Venkatesh et al., 2003) }\end{array}$ \\
\hline
\end{tabular}

UTAUT is a powerful model that provides a unified theoretical basis for technology adoption to explain user behaviour in several areas (Venkatesh et al., 2003). Several studies have shown that the model can explain $70 \%$ of the variance in the behavioural intention to use technology, $40 \%$ of the variance in the usage of technology. The model consists of four main variables: performance expectations, effort expectancy, social influence, and facilitating conditions. Gender, age, experience, and voluntary to use as moderators are expected to mitigate the effects of these basic behavioural beliefs on behavioural intentions and systems adoption, as shown in Fig. 1.

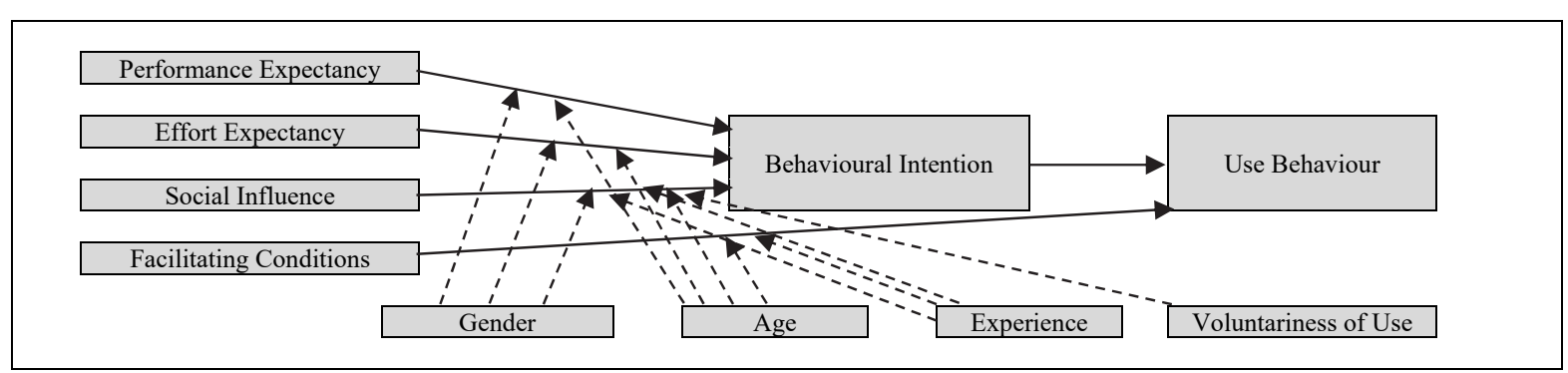

Fig. 1. UTAUT Model 
Table 2

The eight component models and theories of the UTAUT model

\begin{tabular}{ll}
\hline Model or Theory & Authors \\
\hline The Reasoned of Theory Action (TRA) & (Sheppard et al., 1988; Davis et al., 1989) \\
The technology acceptance model (TAM) & (Davis, 1989; Davis et al., 1989; Venkatesh \& Davis, 2000) \\
$\begin{array}{l}\text { The Motivational Model (MM) } \\
\text { Theory of planned behaviour (TPB) }\end{array}$ & (Davis et al., 1989) \\
$\begin{array}{l}\text { A Combined Model of the Theory of Planned Behaviour and } \\
\text { the Technology Acceptance Model (TAM-TPB) }\end{array}$ & (Taylor \& Todd, 1995) \\
$\begin{array}{l}\text { The Model PC of Utilization (MPCU) } \\
\text { Innovation diffusion theory (IDT) }\end{array}$ & (Thompson et al., 1991) \\
Social Cognitive Theory (SCT) & (Rogers, 1983) \\
\hline
\end{tabular}

\subsection{Trust}

Feeling insecure is one of the barriers to using new applications. Especially if you are dealing with sensitive data such as financial statements that any mistake in it leads to an impact on the financial position of the company or a mistake in an investment decision. Thus, the trust acts as a critical role in influencing users' using technology-based systems in question (e.g. XBRL tools). Therefore, the current study assumes that trust is an important factor in predicting the behavioural intentions of users towards the use of XBRL tools. In this research context, trust can be defined as the user's belief that the XBRL tools providers behave ethically in practising their business (Pavlou \& Fygenson, 2006; Chao, 2019), XBRL tool shall be accredited and certified in compliance with the XBRL specifications.

From the perspective of the model of adopting technology-based systems, the trust can influence the personal satisfaction of users to use a particular system (Asiati et al., 2019). For this reason, the trust in tools influences satisfaction in the XBRL tools in terms of accuracy, speed, time-saving which affects the user conviction in the XBRL tools (Al-Rawashdeh, 2011). Furthermore, it affects also user satisfaction emerging from the experience with the demo XBRL tools (Fei et al., 2017). Besides, trust is a central component of Social Exchange Theory (Roloff, 1981). If an XBRL tool is perceived to be trusted for the user more likely to maintain the exchange, relationship with the respective XBRL tools providers.

This trend coincided with the relationship between trust and the intention to use XBRL tools, with a high level of trust between users contributing to a high level of intention to use the XBRL tool. Trust is critical in XBRL tools as it affects perceived tool quality and defines user trust in the use of XBRL tools. Investment decisions, for example, depending on the outcome of the disclosure, which in turn depends on the XBRL tools. Trust in applications was found to influence conviction in the previous study (Carter et al., 2011; Nourallah et al., 2019). Therefore, the hypotheses are formed as below:

\section{$\mathrm{H}_{1}$ : Trust has a significant influence on the behaviour intentions of users to XBRL tools.}

$\mathrm{H}_{2}$ : Trust has a significant influence on the satisfaction of users to use XBRL tools.

\subsection{Effort Expectancy and Performance Expectancy}

Variables in models differ insignificance. The UTAUT model, according to these criteria, is no exception. According to Venkatesh et al. (2003), Performance and effort expectations are considered to be strong variables in the model in their impact on users' behavioural intentions to adopt technology-based systems. Accordingly, this research assumes that performance expectations and effort expectancy are key determinants of behavioural intentions towards the acceptance and adoption of XBRL tools. From the available data, the use of performance expectations and effort expectations as a direct determinant of the behavioural purpose of the XBRL tools in this research is strong justification, leading to the following hypotheses:

\section{$\mathrm{H}_{3}$ : Effort expectancy has a significant influence on the behavioural intentions of users to use XBRL tools.}

$\mathrm{H}_{4}$ : Performance expectancy has a significant influence on the behavioural intentions of users to XBRL tools.

\subsection{Satisfaction}

Although trust is a state of personal conviction, satisfaction is a feeling that arises from user interaction with applications. Satisfaction factor tests the evaluation of the encounter, including the effort and performance expectancy associated with the application or tools used in the tagging or validation or analysing, which can be considered as one of the most important predictors of their subsequent behaviour (Taylor \& Strutton, 2010). Users need to be satisfied with the positive value perceived by the XBRL tools. Satisfaction is a mediating factor for predicting users' behavioural intentions towards the use of XBRL tools. In the point of view of technology-based systems, user satisfaction may have a significant effect on user behaviour's desire to use a specific XBRL based system. (Bao, 2015; DeLone \& McLean, 2016).

Oliver (1981) defined satisfaction "as a summary of the psychological state resulting when the emotion surrounding disconfirmed expectations is coupled with the consumer's prior feelings about the consumption experience." According to DeLone and McLean (2016), This satisfaction is the degree to which users are satisfied with tagging, validation and analyses services. Consent meanings have different contexts, several linguistic definitions exist for pleasure, and together they make the meaning 
rich and simple. In this study, satisfaction is described as satisfaction with something and satisfaction with something. For example, satisfaction in a specific XBRL tool and satisfaction about a specific XBRL tool (continuous satisfaction). Chao (2019) stated Effort expectancy and effort expectancy had significant effects on satisfaction. Besides, Asiati et al. (2019) that trust affected satisfaction. As a result, this research hypothesized that user satisfaction rates could significantly influence users' behavioural intentions to use XBRL tools, the following hypotheses were suggested.

$\mathrm{H}_{5}$ : Effort expectancy has a significant influence on the user's satisfaction with and about XBRL tools.

$\mathrm{H}_{6}$ : Effort expectancy has a significant influence on the user's satisfaction with and about XBRL tools.

$\mathrm{H}_{7}$ : Satisfaction has a significant influence on the behavioural intentions of users to use XBRL tools.

3. Research Instrument and Research Methodology

\subsection{Research instrument}

To complete this study, the research instrument was built to be divided into two parts. In the first section, demographic statistics were given on a nominal scale. The questionnaire gathered basic information on the characteristics of the respondent, such as age, gender, employment, occupation and experience. The second part, containing 21 items, was used to calculate the five factors used in the research model (Fig. 2). These five factors have been identified as endogenous variables (effort expectancy, Effort expectancy, trust, satisfaction, and behavioural intentions to use XBRL tools). Each factor is measured by several items. In order to measure the factors involved in this study, a 5-point Likert scale was implemented to obtain questionnaire responses. The Likert scale consisted of five answer options, starting from "strongly disagree" (mapped to No. 1) to "strongly agree" (mapped to No. 5). After evaluating similar research using the UTAUT model as their theoretical basis, the study method was designed to collect data from the respondents with it (i.e., effort expectancy, trust, effort expectancy, satisfaction, and behaviour intentions to use XBRL tools). Similarly, the measures relevant to this study have been established. Some of the original factors have been taken from the UOTAUT model; other factors have been taken from related studies in the sense of the adoption of technology and information systems, see Table 3 below:

Table 3

Model factors

\begin{tabular}{lcl}
\hline Factor & No of items & Reference \\
\hline Effort expectancy & 5 items & (Venkatesh et al., 2003; Chao, 2019) \\
Effort expectancy & 4 items & (Venkatesh et al., 2003; Chao, 2019) \\
Trust & 5 items & (Carter et al., 2011; Asiati et al., 2019) \\
Satisfaction & 5 items & (Oliver, 1981; DeLone \& McLean, 2016; Fei et al., 2017) \\
Intention & 2 items & (Venkatesh et al., 2003; Rawashdeh \& Selamat, 2013; Chao, 2019) \\
\hline
\end{tabular}

Detailed sections and items are displayed in sequence in Appendix 1. According to Al-Rawashdeh (2011), If the questionnaire has been modified, it is preferable to conduct a pilot study to improve the validity of the questionnaire and to verify the accuracy of all measurement elements. After that, the reliability test was performed using Alpha Cronbach, with an acceptable minimum of 0.7 (Bland \& Altman, 1997). A total of 35 responses have been processed and analysed. Acceptable reliability values ranged from 0.75 to 0.84 , which are compatible with the minimum values of Alpha Cronbach. Such findings showed that the questionnaire was primed, accurate and accessible to collect data from the respondents. The coronavirus (COVID-19) outbreak has stimulated many researchers to conduct online surveys, which mainly rely on online convenience samples, emails, or social media sites where participants choose themselves. Studies for generalizing the selection of a random sample representative of the general population are important, but this does not mean that work in which findings can not be generalized does not provide a value, and its utility can be much more than generalized study.

\section{Data Analysis and discussions}

To develop a new model, PLS-SEM can be used because it is used in the initial stages of model development or theory. Because it helps the researcher to explain the reliability and reliability of the measurement model and its structure, therefore PLS-SEM was used in this research. Empirical data were collected via an online survey, in which messages were sent to potential respondents to participate, and colleagues in the participating field were invited to participate, and others were encouraged to participate. Respondents are totally anonymous and no information relating to their identity has been obtained, except for demographic details, which is not connected to the identification of the respondent. The privacy of the respondents was therefore completely protected.

\subsection{Demographic Characteristics of respondents}

Respondents were told that all information was confidential and that no one could access it and in any way know the identity of the respondents. The questionnaire was not long to increase the response rate. 281 questionnaires were collected and 14 incomplete questionnaires were rejected, leaving 267 valid questionnaires to be used for statistical analysis. Respondent- 
related demographic data are shown in Table 3. The percentage of males participating in the survey and using the XBRL tool was higher than females, at a rate of $70.4 \%$ to $29.6 \%$, respectively. The most common age group for the use of XBRL tools was between 17 and 34. Most of the survey respondents and users of XBRL tools were holders of a bachelor's degree. 59.6\% described themselves as accountants 70.8\%. XBRL is a newcomer in Saudi Arabia. 74.9 of the participants had a two-year period of use of XBRL (Table 4).

Table 4

Demographic information

\begin{tabular}{|c|c|c|c|c|c|}
\hline & Item & Frequency & Percent & Valid Percent & Cumulative Percent \\
\hline \multirow{3}{*}{ Gender } & Female & 79 & 29.6 & 29.6 & 29.6 \\
\hline & Male & 188 & 70.4 & 70.4 & 100.0 \\
\hline & Total & 267 & 100.0 & 100.0 & \\
\hline \multirow{6}{*}{ Age } & $<55$ & 13 & 4.9 & 4.9 & 4.9 \\
\hline & $17-24$ & 79 & 29.6 & 29.6 & 34.5 \\
\hline & $25-34$ & 79 & 29.6 & 29.6 & 64.0 \\
\hline & $35-44$ & 68 & 25.5 & 25.5 & 89.5 \\
\hline & $45-54$ & 28 & 10.5 & 10.5 & 100.0 \\
\hline & Total & 267 & 100.0 & 100.0 & \\
\hline \multirow{5}{*}{ Educational } & Bachelor & 159 & 59.6 & 59.6 & 59.6 \\
\hline & Diploma & 13 & 4.9 & 4.9 & 64.4 \\
\hline & Master (MA, Msc) & 40 & 15.0 & 15.0 & 79.4 \\
\hline & PH.D & 55 & 20.6 & 20.6 & 100.0 \\
\hline & Total & 267 & 100.0 & 100.0 & \\
\hline \multirow{5}{*}{ Profession } & Accountant & 189 & 70.8 & 70.8 & 70.8 \\
\hline & Analyst & 38 & 14.2 & 14.2 & 85.0 \\
\hline & Auditor & 27 & 10.1 & 10.1 & 95.1 \\
\hline & Investor & 13 & 4.9 & 4.9 & 100.0 \\
\hline & Total & 267 & 100.0 & 100.0 & \\
\hline \multirow{4}{*}{ Usage Years } & $<3$ & 26 & 9.7 & 9.7 & 9.7 \\
\hline & 1 year & 200 & 74.9 & 15.4 & 84.6 \\
\hline & 2 years & 41 & 15.4 & 74.9 & 100.0 \\
\hline & Total & 267 & 100.0 & 100.0 & \\
\hline
\end{tabular}

\subsection{Measurement Model Evaluation}

The factor analysis and reliability test had been carried. The rotated factor matrix that resulted from varimax rotated the principal axis factor of the independent and dependent variables, 1.0 eigenvalue cut-off scale was used. It suggests that all factors with eigenvalues $>1.0$ are chosen. As presented in Table 4, indicating that three independent, one mediating variable and one dependent variable had been selected, in addition to listing their factor loadings (Table 5).

Table 5

Rotated factor matrix and Cronbach's $\alpha$

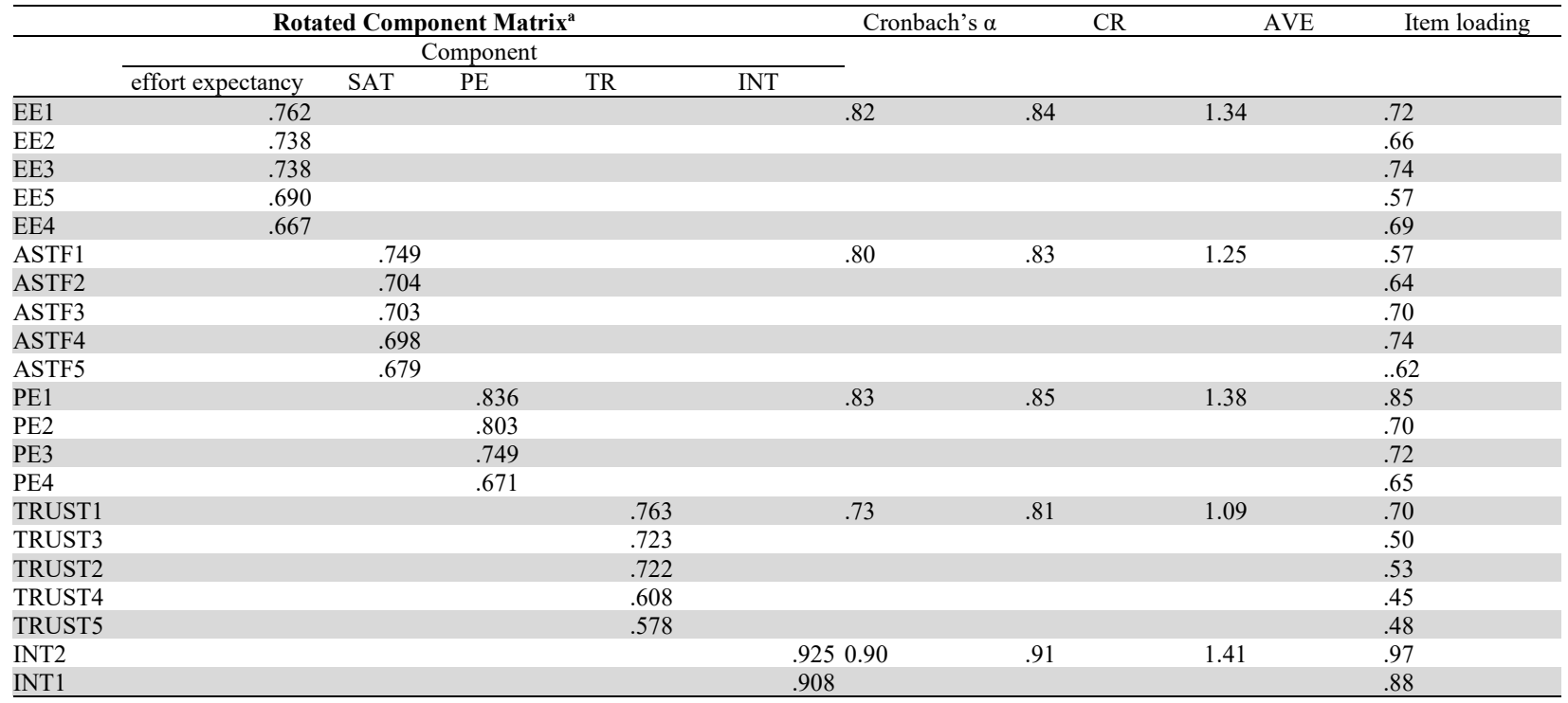

Extraction Method: Principal Component Analysis.

Rotation Method: Varimax with Kaiser Normalization.

a. Rotation converged in 6 iterations. 
The factor loadings for the information quality ranged from 0.73 to 0.90 , for the effort expectancy from .667 to .763 , for satisfaction from .679 to .749 , for effort expectancy from .671 to .836 , for trust from .578 to 0.86 and for intention .908 to 925. As all factor loadings were found to be at an acceptable and qualified further analysis. Construct reliability is used to evaluate the factor that is evaluated by its items using Cronbach's alpha and CR. The internal reliability was evaluated by examining the Cronbach's alpha and composite reliability (CR) values for all constructs. To measure the CV, the average variance extracted (AVE) was measured. The analysis results are presented in Table 4. The findings refer that estimating Cronbach's $\alpha$ which varied between 0.73 and 0.90 and CR started from .81 for effort expectancy to .91 for intention. Every item had been evaluated separately to ensure item reliability and convergent validity. As noted from the results, the values exceeded the cut-off point specified in this paper, which is 0.7 (Hair Jr et al., 2010). This, in turn, reflects high internal reliability, consistent with previous studies. Finally, with values exceeding the recommended values (.5), the AVE values for each factor in the model ranged from 1.09 to 1.41 . In Table 4 , the evaluated factor loadings range started from .578 to .925 , and were statistically significant $(\mathrm{p}<0.05)$.

\subsection{Model Fit Measures and Cutoff Criteria}

Reviewing Fit statistical data listed in Table 6, it has been found that all fit statistics suggest an excellent fit. Core fit statistics showed a Chi-square value equivalent to 276.851, 0.001 as p-value, 276.851 as CMIN, 176 as DF, 1.573 as CMIN / DF, 0.952 as CFI, 0.074 as SRMR, 0.046 as RMSEA, and 0.707 as PClose (Table 5). All such numbers suggest an excellent match according to the generally proposed criteria (Gaskin \& Lim, 2016).

Table 6

Fit Measures and Cutoff Criteria

\begin{tabular}{|c|c|c|c|c|c|c|c|}
\hline \multirow{2}{*}{\begin{tabular}{l}
\multicolumn{2}{c}{ Measure } \\
$\mathrm{CMIN}$
\end{tabular}} & \multirow{2}{*}{\begin{tabular}{|l} 
Estimate \\
276.851
\end{tabular}} & \multirow{2}{*}{$\begin{array}{c}\text { Threshold } \\
--\end{array}$} & \multirow{2}{*}{$\begin{array}{c}\text { Interpretation } \\
--\end{array}$} & \multicolumn{4}{|c|}{ Cutoff Criteria* } \\
\hline & & & & Measure & Terrible & Acceptable & Excellent \\
\hline DF & 176 & -- & -- & & & & \\
\hline CMIN/DF & 1.573 & Bet. 1 and 3 & Excellent & CMIN/DF & $>5$ & $>3$ & $>1$ \\
\hline CFI & 0.952 & $>0.95$ & Excellent & CFI & $<0.90$ & $<0.95$ & $>0.95$ \\
\hline SRMR & 0.074 & $<0.08$ & Excellent & SRMR & $>0.10$ & $>0.08$ & $<0.08$ \\
\hline RMSEA & 0.046 & $<0.06$ & Excellent & RMSEA & $>0.08$ & $>0.06$ & $<0.06$ \\
\hline PClose & 0.707 & $>0.05$ & Excellent & PClose & $<0.01$ & $<0.05$ & $>0.05$ \\
\hline
\end{tabular}

In order to determine the viability of their measured values, it is essential to estimate the fitness of the different parameters for the research model in order to start with the expansion of the expected estimations of the parameters. Generally, the estimations of the parameter show that if the model is consistent with the underlying theory. According to Hu and Bentler (1999), in the analysis of covariance structure the cutoff criteria for fit indexes (Table 5) are a combination of CFI $>0.95$ and $\mathrm{SRMR}<0.08$, add the RMSEA $<0.06$ to further solidify evidence. Results showed that the estimates were excellent (Table 5), based on the criteria proposed by $\mathrm{Hu}$ and Bentler (1999), this refers to the fact that the model is fit for this research. The critical ratio and significance of path coefficient, when the critical ratio (CR) is $>1.96$ for a regression weight for a specific hypothesis, the path will be significant at the .05 level or less, this refers that estimated path parameter for such hypothesis is significant on this path. Tucker-Lewis coefficient measure also estimated, .943 as TLI. Tucker-Lewis coefficient was discussed in the context of analysis of moment structures and is known as the Bentler-Bonett non-normed fit index (NNFI) (Bentler, 1990). The typical range for TLI lies between zero and one, but it is not limited to that range. TLI values close to one indicate a very good fit.

\subsection{Statistical Findings and Hypotheses Testing}

PLS-SEM regression was used to examine the assumed effect in the model for Trust, effort expectancy and effort expectancy factors on the behavioural intentions of users to use XBRL tools (Fig. 2). For example, to examine the moderating effect in the model, effort expectancy, effort expectancy, and trust as predictors and satisfaction as a mediating factor to predict the behaviour intentions of users to use XBRL tools.

After establishing an acceptable model for this research, the researcher assessed the structural model explaining the path diagram in Fig. 2. Table 7 reports the regression weights. The SEM analysis results indicate that H1, H5, H6 and H7 have been supported (Table 7). To test the statistical significance of the parameter estimates from SEM, the test statistic is the critical ratio (C.R) and p-values. The probability of getting a critical ratio as large as the critical ratio in absolute value is less than $\mathrm{p}$-value. In other words, the regression weight for information in the prediction of specific factor is significantly different from zero at the p-value level (two-tailed).

Concerning a significance level of 0.05 or less, the critical ratio (C.R) requires being greater than \pm 1.96 (Hair Jr et al., 2010 ). Any critical ratio level below this indicates that the parameter can be identified insignificant for the research model. 
Table 7

Regression Weights: (Group number 1 - Default model)

\begin{tabular}{|c|c|c|c|c|c|c|c|}
\hline & & & Estimate & S.E. & C.R. & $\mathrm{P}$ & Hvpothesis \\
\hline $\mathrm{EE}$ & $\rightarrow$ & STF & 0.257 & 0.063 & 4.109 & $* * *$ & $\mathrm{H} 5$ \\
\hline PE & $\rightarrow$ & STF & 0.209 & 0.049 & 4.25 & $* * *$ & H6 \\
\hline Trust & $\rightarrow$ & STF & 0.02 & 0.032 & 0.632 & 0.527 & $\mathrm{H} 2$ \\
\hline STF & $\rightarrow$ & INT & 1.08 & 0.242 & 4.468 & $* * *$ & H7 \\
\hline Trust & $\rightarrow$ & INT & 0.191 & 0.071 & 2.695 & 0.007 & H1 \\
\hline $\mathrm{EE}$ & $\rightarrow$ & INT & -0.037 & 0.135 & -0.272 & 0.786 & H3 \\
\hline PE & $\rightarrow$ & INT & -0.061 & 0.108 & -0.565 & 0.572 & $\mathrm{H} 4$ \\
\hline
\end{tabular}

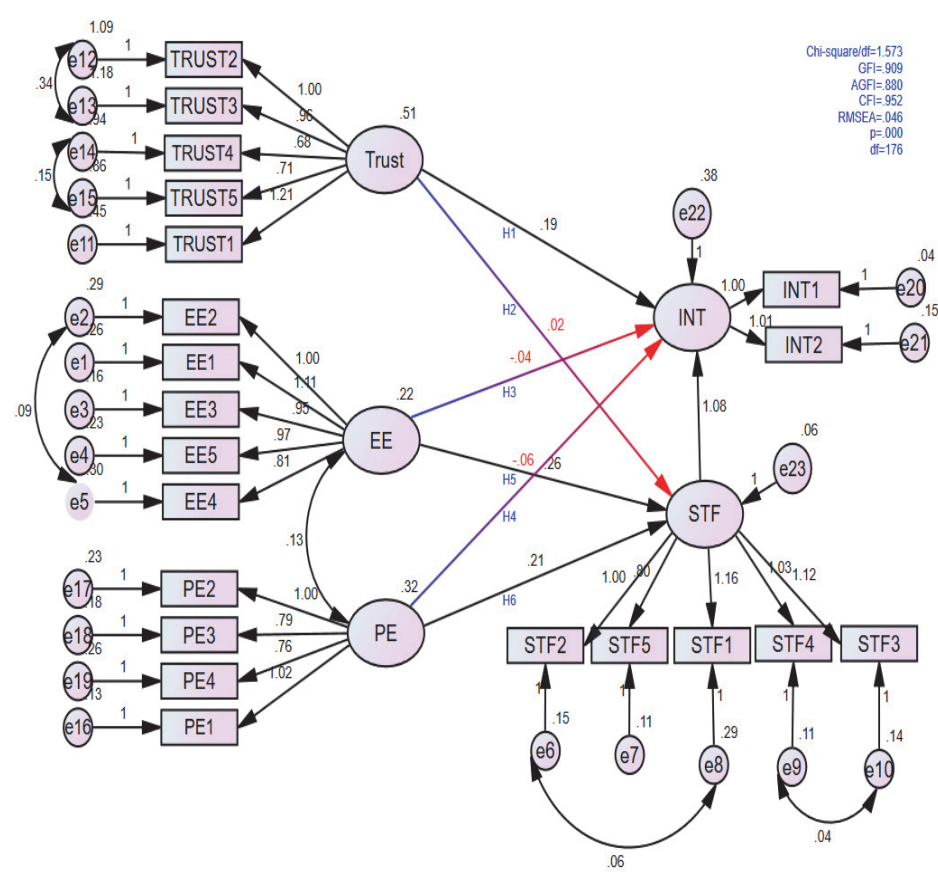

Fig. 2. Research Model

Estimating trust impact on intent (H1) was.191 when trust increases by 1 . The intent increases by.191 (with C.R. = 2.695; $\mathrm{p}<0.001$ ), which was significant, and this result is interesting (Table 6). It is consistent with the suggestion made by Carter et al. (2011) in the context of the exchange of sensitive data. XBRL tools are used to process sensitive financial data for disclosure or analysis. If the trust in the XBRL tools is not high, it will not be trusted, and this makes sense for the rational user. Often, trust (e.g. accuracy, error-free, up-to-date, certified) is helpful for users of XBRL tools to submit valid XBRL instance documents or to make more reliable alternative comparisons between financial statements.

Estimating to impact trust $(\mathrm{H} 2)$ on satisfaction was 0.02 when Interactivity goes up by 1 , E-trust goes up by 0.02 (with C.R. $=0.632 ; \mathrm{p}=0.527$ ), which was not significant (Table 6). Alfin et al. (2013) have shown that trust has no significant impact on satisfaction. XBRL has received considerable attention in recent years. Results show that trust in XBRL tools exceeds satisfaction and is a priority for users when deciding to use it. Users will use the licensed tool regardless of their satisfaction with the XBRL tools. To summarize the results, it has been shown that there is a direct effect of trust on users' intention to use XBRL tools, but not an indirect effect through satisfaction as a mediating factor.

The third hypothesis (H3) has been rejected, the estimating was -0.037 with C.R. $=-0.272$ and $p=0.786$ and the fifth (H5) accepted, estimating was 0.257 with C.R. $=04.109$ and $\mathrm{p}<0.001$ (Table 6). In other words, in the research model of this study, we may consider a complete mediation of satisfaction in the relationship between effort expectancy and intention of users to use XBRL tools, which is consistent with some findings (Miladinovic \& Hong, 2016; Handoko et al., 2018; Chao, 2019). At the other hand, the effort expectancy is supposed to have an indirect effect on the intention by satisfaction. The results of this study are also consistent with those of the previous related research (Chao, 2019). The value of satisfaction during effort expectancy has a major effect on XBRL tools developers. Therefore, the creation and review of XBRL software for the tagging and analysis of financial statements will rely more on the effort expectancy of the XBRL tools. Because by using XBRL tools, they submit financial information or make a financial transaction that has an impact on their financial future. It may also make errors if the XBRL method is difficult to use, leading to financial losses and a waste of time. These findings indicate that effort expectancy is a critical factor in terms of satisfaction with the tools used, especially in the early stages of the use of XBRL tools. Apparently, this is a new contribution to the existing theory of acceptance of XBRL tools. 
The fourth hypothesis (H4) was rejected and the sixth (H6) accepted. Furthermore, a complete mediation of satisfaction in the relationship between performance expectancy and intention of users to use XBRL tools could be found in the research model of this study. Nevertheless, the relationship between performance expectancy and intention of users to use XBRL tools (H4) is not significant (C.R. $=-0.565$ and $\mathrm{p}=0.572$ ), which means that there is no intention effect on performance expectancy (Table 6). However, the relationship between performance expectancy and intention of users to use XBRL tools (H6) is significant, with an estimation of 0.209 for C.R. $=4.25$ and $p<0.001$, respectively. It may be due to the fact that users of XBRL tools will be comfortable with their use of the tool and that it will help them improve their job performance before they plan to use XBRL tools. This is illustrated in the $\mathrm{H} 6$ by a full mediation of satisfaction between performance expectations and the intention of users to use XBRL tools. The results are consistent with previous studies (Chao, 2019). Then, performance expectancy can have an indirect impact on the decision to use it by satisfaction. Basically, the purpose of XBRL tools is to conduct different activities, whether financial disclosure or data analysis. Thus, if the user is not satisfied with the expected results of this tool, the user will not use it.

The final purpose of the current study is to investigate the complete mediation of satisfaction with the intention of users to use XBRL tools. Estimated effect satisfaction on intention $(\mathrm{H} 7)$ was 1.08 when (with C.R. $=4.468 ; \mathrm{p}<0.001)($ Table 6$)$, which was very significant (Bao, 2015; DeLone \& McLean, 2016; Chao, 2019). This is an interesting result; it appears to be a new confirmation of what exists in the theory. In previous work, Alfin et al. (2013) found that trust had led to the intention of users to use XBRL tools.

\subsection{The Predictive and Explanatory Power of the Model}

The results of this study provide support for the research model. The major aim for satisfaction to use as a mediating variable of the intention of users to use XBRL tools and it is the ability to explain and predict user intention, based on merely three theoretical factors, namely, trust, performance expectancy and effort expectancy. Four hypotheses were supported by these interesting findings. Trust has a direct impact on the intention of users to use XBRL tools, not an indirect impact on satisfaction. Besides, performance expectations and effort expectations have shown a positive impact on satisfaction as an indirect impact on the intention of users to use XBRL tools. Regarding the predictive power of satisfaction, the results showed a strong interpretation of the intention of users to use XBRL tools by satisfaction.

Such effects provide a number of essential insights into the determinants of the use of XBRL tools. First, its satisfaction with XBRL tools is the major determinant of the user's intent. Second, the expectation of effort is a significant, highly indirect determinant of intent. Third, the expectation of performance is important as an indirect determinant of intent. Last but not least, trust is a highly direct determinant of intent. In general, satisfaction as a mediating variable between the variable and intention of users to use XBRL tools, rather than having a direct impact from the variables of the independents. Additionally, future research may consider including such an alternative approach.

\subsection{Discussion}

The purpose of this study was to identify factors that influence users' behavioural intentions to use XBRL tools. According to the researcher's experience, the factors influencing the use of analytical instruments have not been examined before or at least in this way. Therefore, this research model incorporates specific elements such as trust and satisfaction in extending the original model to give a stronger predictive capacity to the model. The results of the analysis showed the factors affecting the behavioural intention of users to use XBRL tools. Satisfaction came in the first order in the effect, then immediately followed by effort expectancy the third arrangement was performance expectancy. The last order in effect was for trust. These results can be explained as follows.

Four variables clarified the variation in behavioural intentions of the XPRL tools. Where trust had a direct effect on the behavioural intentions of using the XPRL tools, and these results were consistent with the previous findings as mentioned above. The results supported trust and satisfaction with the ability to be the main variables in the model.

The nature of the relationship lies in the disappearance of the trust gap between users and developers, the existence of goodwill messages between them, and the disappearance of the factor of mistrust and fear among users, which leads them to form intent directly without the need for variable mediation, as the results have shown. Trust of the user in one of the XPRL tools does not mean his utter intention of users to use XBRL tools to use this tool. Instead, trust acts here as a filter for preferred tools in order to make more evaluations of them, such as performance expectancy and effort expectancy.

When satisfaction is combined with trust, the aim is to use one of the XPRL tools in question. Satisfaction is not self-constructed, but satisfaction is created as a consequence of the knowledge or preconceived notion of the performance expectancy and effort expectancy of the tool. Therefore, in the beginning, and then later, they are happy with it. The consumer has often reported outcomes of desired satisfaction in order to prevent the occurrence of mistakes and waste of time or the ability to achieve constructive and motivating outcomes as a result of the use of the tool in question. For example, the consumer does not seek the approval of the developer. The willingness of the user to use a resource to achieve a particular task is measured by trust-based intentions and experience-based satisfaction. As assumed in the original model, expectation of performance 
and expected effort confirmed the existence of a strong influence on users' behavioural intentions to use XBRL tools through satisfaction. In addition, compatibility with other research was achieved with these famous variables.

Among the outstanding results in this model is the role of the variable expectation of performance, and the expectation of effort is their relationship to satisfaction. This means that the use of XBRL tools is associated with the user's satisfaction of these tools whenever the users use them in their work. This result was also consistent, as with previous results, with a group of researchers in this context. Based on the findings from this study, XBRL tools are becoming an increasingly crucial tool for companies to disclose. When users find that XBRL tools have low expectations of effort and high expectations of performance. It is expected to consider the tool to improve their disclosure and decision, enhance their satisfaction towards XBRL tools and user behavioural intentions to use XBRL tools. For example, providing evidence explained in detail with adding pictures for each step in addition to providing comprehensive videos explaining the use of the XBRL tools in detail, and this is available to users before proceeding to purchase the XBRL tools. This would improve the satisfaction of potential users of the XBRL tools.

\subsection{Limitations and Future Research}

Due to the scarcity of previous studies which have examined the subject in general and in Saudi Arabia in particular. The study focuses on all users of XBRL tools in general, and studies can focus on independent auditors, accountants, analysts, and even business owners. It is also claimed that the time after Coronavirus (COVID-19) was not the same as before Coronavirus (COVID-19) (pre and post corona) the study was strongly affected by the isolation imposed on citizens, including researchers and respondents in this study. The online questionnaire was also used and this form of questionnaire allows the respondents to choose themselves to be a part of the survey. This does not make it possible to generalise the results. Potential studies are therefore advised to use paper questionnaires and random surveys over a long period, as opinions that shift due to the accumulation of respondents' experiences.

\subsection{Conclusion}

For the purposes of this study, a detailed model was built to describe user behavioural intentions to use XBRL resources where the dependency on the UTAUT model was depended on. Some of the variables that were mainly present in this model have been abandoned and, in exchange, new variables have been introduced that match the adoption of the XBRL tools. The model consists of five variables, the effort expectancy, performance expectancy, trust, satisfaction, and behavioural intentions of users to use the XBRL tools. After the questionnaire was developed for study purposes, it was used to collect data via an online questionnaire and 267 questionnaires were analysed. The results of the research showed that the study model had high internal reliability and accuracy, demonstrating the model's ability to clarify. The results showed that the variables applied to the model, such as trust and satisfaction, had a strong impact on the behavioural intentions of using the XBRL tools. In addition to the strong influence, effort expectancy and effort expectancy had on users' behavioural intentions to use XBRL tools through satisfaction.

This study just knocks on the door, XBRL is still in progress and the XBRL tools that support its use are in progress. Understanding the factors that influence users' behavioural intentions to use XBRL tools could be helpful for potential developers of XBRL tools, as may be useful from the academic point of view for researchers interested in this matter.

\section{References}

Ajzen, I. (1991). The theory of planned behavior. Organizational behavior and human decision processes, 50(2), $179-211$. Al-Rawashdeh, A. A. (2011). Diffusion of xbrl innovation model of adoption and usage. Universiti Utara Malaysia.

Alfin, R., Alhabsji, T., \& Umar Nimran, S. (2013). Effect of service quality and product quality to corporate image, customer's satisfaction and customer's trust. IOSR Journal of Business and Management, 9(6), 1-9.

Alkhatib, E. a., Ojala, H., \& Collis, J. (2019). Determinants of the voluntary adoption of digital reporting by small private companies to companies house: Evidence from the uk. International Journal of Accounting Information Systems, 34, 100421.

Almaiah, M. A., Alamri, M. M., \& Al-Rahmi, W. (2019). Applying the utaut model to explain the students' acceptance of mobile learning system in higher education. IEEE Access, 7, 174673-174686.

Althunibat, A., Zahrawi, A. A., Tamimi, A. A., \& Altarawneh, F. H. (2019). Measuring the acceptance of using enterprise resource planning (erp) system in private jordanian universities using tam model. International Journal of Information and Education Technology, 9(7).

Ansary, M. E., Oubrich, M., Orlando, B., \& Fiano, F. (2020). The determinants of xbrl adoption: A meta-analysis. International Journal of Managerial and Financial Accounting, 12(1), 1-24.

Asiati, D. I., Umar, H., \& Sitinjak, T. (2019). The effects of service quality, image and trust on satisfaction and its impact on syari $^{-}$ah bank customer loyalty in palembang. Business and Economic Research, 9(1), 295-316.

Baby, A., \& Kannammal, A. (2020). Network path analysis for developing an enhanced tam model: A user-centric e-learning perspective. Computers in Human Behavior, 107, 106081.

Bandura, A. (1986). Social foundations of thought and action. Englewood Cliffs, NJ, 1986, 23-28. 
Bao, J. (2015). The impacts of e-service quality on customers' repurchase intention in platform online retailing: An empirical investigation. Paper presented at the Wuhan International Conference on E-Business 2015 Proceedings.

Bentler, P. M. (1990). Comparative fit indexes in structural models. Psychological bulletin, 107(2), 238.

Bland, J. M., \& Altman, D. G. (1997). Statistics notes: Cronbach's alpha. Bmj, 314(7080), 572.

Blankespoor, E. (2019). The impact of information processing costs on firm disclosure choice: Evidence from the xbrl mandate. Journal of Accounting Research, 57(4), 919-967.

Carter, L., Shaupp, L. C., Hobbs, J., \& Campbell, R. (2011). The role of security and trust in the adoption of online tax filing. Transforming Government: People, Process and Policy.

Chao, C.-M. (2019). Factors determining the behavioral intention to use mobile learning: An application and extension of the utaut model. Frontiers in psychology, 10, 1652.

Chouhan, V., \& Goswami, S. (2015). An analysis of xbrl adoption in india using technology acceptance model. IUP Journal of Information Technology, 11(3).

Compeau, D. R., \& Higgins, C. A. (1995). Computer self-efficacy: Development of a measure and initial test. MIS Quarterly, 19(2), 189-211.

Davis, F. D. (1989). Perceived usefulness, perceived ease of use, and user acceptance of information technology. MIS quarterly, 319-340.

Davis, F. D., Bagozzi, R. P., \& Warshaw, P. R. (1989). User acceptance of computer technology: A comparison of two theoretical models. Management science, 35(8), 982-1003.

DeLone, W. H., \& McLean, E. R. (2016). Information systems success measurement. Foundations and Trends ${ }^{\circledR}$ in Information Systems, 2(1), 1-116.

Efimova, O., Rozhnova, O., \& Gorodetskaya, O. (2019). Xbrl as a tool for integrating financial and non-financial reporting. Paper presented at the The 2018 International Conference on Digital Science.

Fei, H., Huan, W., \& Zi, Y. (2017). Empirical study on measuring the information satisfaction of online xbrl financial reports. Communication of Finance and Accounting, 2017(31), 6.

Gaskin, J., \& Lim, J. (2016). Model fit measures. Gaskination's StatWiki, 1-55.

Gitau, M. W. (2016). Application of the utaut model to understand the factors influencing the use of web 2.0 tools in e-learning in kenyan public universities. University of Nairobi.

Hair Jr, J., Black, W., Babin, B., Anderson, R., \& Tatham, R. (2010). Sem: An introduction. Multivariate data analysis: A global perspective, 5(6), 629-686.

Handoko, B. L., Ariyanto, S., \& Warganegara, D. L. (2018). Perception of financial auditor on usage of computer assisted audit techniques. Paper presented at the 2018 3rd International Conference on Computational Intelligence and Applications (ICCIA).

Hu, L. t., \& Bentler, P. M. (1999). Cutoff criteria for fit indexes in covariance structure analysis: Conventional criteria versus new alternatives. Structural equation modeling: a multidisciplinary journal, 6(1), 1-55.

Ilias, A., Ghani, E. K., Baidi, N., \& Abdul, R. (2020). Xbrl adoption: An examination on the malaysian business reporting system (mbrs). Humanities, 8(2), 202-214.

Khechine, H., Raymond, B., \& Augier, M. (2020). The adoption of a social learning system: Intrinsic value in the utaut model. British Journal of Educational Technology.

Lakovic, T., Rondovic, B., Backovic-Vulic, T., \& Ivanovic, I. (2018). The determinants of xbrl adoption: An empirical study in an emerging economy. Paper presented at the European, Mediterranean, and Middle Eastern Conference on Information Systems.

Liu, C., Luo, X. R., \& Wang, F. L. (2017). An empirical investigation on the impact of xbrl adoption on information asymmetry: Evidence from europe. Decision Support Systems, 93, 42-50.

Manrai, R., \& Gupta, K. P. (2020). Integrating utaut with trust and perceived benefits to explain user adoption of mobile payments Strategic system assurance and business analytics (pp. 109-121): Springer.

Miladinovic, J., \& Hong, X. (2016). A study on factors affecting the behavioral intention to use mobile shopping fashion apps in sweden.

Muchlis, F., Primadyan, M., Shauki, E. R., \& Diyanty, V. (2019). Xamining xbrl early adopters: A study of determinants and value relevance. Paper presented at the Asia Pacific Business and Economics Conference (APBEC 2018).

Nourallah, M., Strandberg, C., \& Öhman, P. (2019). Understanding the relationship between trust and satisfaction on mobile bank application. Paper presented at the Proceedings of the 2019 3rd International Conference on E-commerce, E-Business and E-Government.

Oliver, R. L. (1981). Measurement and evaluation of satisfaction processes in retail settings. Journal of retailing, 57(3), 2548.

Patil, P., Tamilmani, K., Rana, N. P., \& Raghavan, V. (2020). Understanding consumer adoption of mobile payment in india: Extending meta-utaut model with personal innovativeness, anxiety, trust, and grievance redressal. International Journal of Information Management, 54, 102144.

Pavlou, P. A., \& Fygenson, M. (2006). Understanding and predicting electronic commerce adoption: An extension of the theory of planned behavior. MIS Quarterly, 30(1), 115-143.

Petersen, F., Jacobs, M., \& Pather, S. (2020). Barriers for user acceptance of mobile health applications for diabetic patients: Applying the utaut model. Paper presented at the Conference on e-Business, e-Services and e-Society. 
Pinsker, R. E., \& Felden, C. (2016). Professional role and normative pressure: The case of voluntary xbrl adoption in germany. Journal of Emerging Technologies in Accounting, 13(1), 95-118.

Rahi, S., Mansour, M. M. O., Alghizzawi, M., \& Alnaser, F. M. (2019). Integration of utaut model in internet banking adoption context. Journal of Research in Interactive Marketing.

Rawashdeh, A., \& Selamat, M. H. (2013). Critical success factors relating to the adoption of xbrl in saudi arabia. Journal of International Technology and Information Management, 22(2), 4.

Rogers, E. M. (1983). Diffusion of innovations (1983): New York: Free Press.

Roloff, M. E. (1981). Interpersonal communication: The social exchange approach.

Sheppard, B. H., Hartwick, J., \& Warshaw, P. R. (1988). The theory of reasoned action: A meta-analysis of past research with recommendations for modifications and future research. Journal of consumer research, 15(3), 325-343.

Taiwo, A. A., Mahmood, A. K., \& Downe, A. G. (2012). User acceptance of egovernment: Integrating risk and trust dimensions with utaut model. Paper presented at the 2012 international conference on computer \& information science (ICCIS).

Taylor, D. G., \& Strutton, D. (2010). Has e-marketing come of age? Modeling historical influences on post-adoption era internet consumer behaviors. Journal of business research, 63(9-10), 950-956.

Taylor, S., \& Todd, P. A. (1995). Understanding information technology usage: A test of competing models. Information systems research, 6(2), 144-176.

Thompson, R. L., Higgins, C. A., \& Howell, J. M. (1991). Personal computing: Toward a conceptual model of utilization. MIS quarterly, 125-143.

Tohang, V., \& Lan, M. (2017). The impact of adoption of xbrl on information risk in representative countries of scandinavian region. Jurnal Keuangan dan Perbankan, 21(4), 197342.

Uyob, R. B., Bahador, K. M. B. K., \& Noh, N. S. B. (2019). The determinants factors of accounting practitioner's attitude towards the use of malaysian business reporting system (mbrs). International Journal of Business and Management, 3(5), 01-10.

Venkatesh, V., \& Davis, F. D. (2000). A theoretical extension of the technology acceptance model: Four longitudinal field studies. Management science, 46(2), 186-204.

Venkatesh, V., Morris, M. G., Davis, G. B., \& Davis, F. D. (2003). User acceptance of information technology: Toward a unified view. MIS quarterly, 425-478.

Wrycza, S., Marcinkowski, B., \& Gajda, D. (2017). The enriched utaut model for the acceptance of software engineering tools in academic education. Information systems management, 34(1), 38-49.

Wu, L., \& Chen, J.-L. (2005). An extension of trust and tam model with tpb in the initial adoption of on-line tax: An empirical study. International Journal of Human-Computer Studies, 62(6), 784-808.

\section{Appendix 1}

Questioner elements

\begin{tabular}{ll}
\hline Factors & Items \\
\hline Effort Expectancy & Learning how to use XBRL tools easy for me. \\
& My interaction with XBRL tools would be clear and understandable. \\
& I find XBRL tools easy to use. \\
It is easy for me to become skilful at using XBRL tools. \\
I would find it easy to get the XBRL tools to do what I want it to do. \\
Using XBRL tools would improve my disclosure or analysis performance. \\
Using XBRL tools increases my chances of achieving a task that is important to me. \\
Using XBRL tools would allow me to accomplish disclosure or analysis tasks more quickly. \\
Using XBRL tools would enhance my effectiveness in disclosure or analysis. \\
I believe that XBRL tools are trustworthy. \\
I trust in XBRL tools. \\
I do not doubt the results of XBRL tools. \\
I would trust XBRL tools to do the job right. \\
I was very content with XBRL tools. \\
I was very pleased with XBRL tools. \\
I was satisfied with the XBRL tools ' efficiency. \\
I felt delighted with XBRL tools. \\
Assuming I have the XBRL tools, I intend to use it. \\
Given that I have the XBRL tools, I predict that I would continue to use it.
\end{tabular}

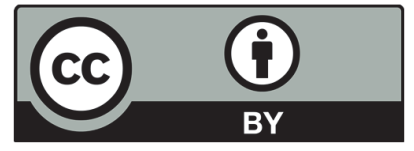

(C) 2021 by the authors; licensee Growing Science, Canada. This is an open access article distributed under the terms and conditions of the Creative Commons Attribution (CC-BY) license (http://creativecommons.org/licenses/by/4.0/). 